\title{
DESENVOLVIMENTO DE UM ARRANJO EXPERIMENTAL DIDÁTICO PARA O ESTUDO DA ESPECTROSCOPIA DE IMPEDÂNCIA ELETROQUÍMICA
}

\author{
Ricardo Macedo Borges Boaventura ${ }^{1}$; Ernando Silva Ferreira ${ }^{2}$; \\ 1. Bolsista PIBIC/FAPESB, Graduando em Bacharelado em Física, Universidade Estadual de Feira de Santana, e- \\ mail: ricardombboaventura@ gmail.com \\ 2. Orientador, Departamento de Física, Universidade Estadual de Feira de Santana, e-mail: \\ ernandofisica@yahoo.com.br
}

PALAVRAS-CHAVE: Espectroscopia de impedância eletroquímica; Instrumentação; Eletroquímica.

\section{INTRODUÇÃO}

$\mathrm{O}$ uso de biossensores em diversas áreas da ciência vem aumentando rapidamente, sobretudo na análise de substâncias, seja para aferição de qualidade ou concentração de determinadas impurezas. Dentre as várias etapas de fabricação de biossensores, destacamos a etapa do estudo da interação entre biomoléculas e substratos sintéticos, que pode ser estudado por diversas técnicas de caracterização. Uma delas é a caracterização por Espectroscopia de Impedância Eletroquímica (EIE) - também conhecida como EIS (do inglês-Electrochemical Impedance Spectroscopy). Esta método de caracterização é um dos mais informativos dentre muitos métodos eletroquímicos recentemente disponíveis no desenvolvimento de sensores de afinidade e de biossensores (BARSOUKOV \& McDONALD, 2005). Ela é especialmente bem aplicada nos sensores baseados em eletrodos modificados por camadas de polímeros semicondutores, bem como nos sensores de afinidade baseados em polímeros condutores (como o polipirrol) molecularmente impressos (MIPs-do inglês Molecularly Imprinted Polymer), que podem ser impressos por moléculas de baixa massa molecular como a teofilina, cafeína ou por grandes moléculas, como proteínas e até mesmo o DNA (BARD \& FAULKNER, 2000).

O conceito de resistência elétrica é, basicamente, a habildade que um circuito apresenta de resistir à passagem de uma corrente elétrica. Da lei de Ohm (equação 1), temos que a resistência é definida pela razão entre a tensâo $\mathrm{V}$ e a corrente $\mathrm{I}$.

$$
R=\frac{V}{I}
$$

No entanto, essa relação so é válida para um resistor ideal. Um resistor ideal obedece à lei de Ohm em qualquer faixa de corrente ou tensão, sua resistência não varia e um sinal em corrente alternada (AC) mantém sua fase ao passar por ele. No mundo real, são encontrados sistemas muito mais sofisticados do que esse e que exibem comportamento bastante complexo. Isso traz a necessidade da introdução do conceito de impedância, que é mais geral do que a resistência.

Supondo um circuito RLC submetido a uma corrente alternada na forma de exponencial complexa $I^{*}=I_{0} e^{i \omega t}$. Pela equação (1), as tensões em cada um desses elementos em série será

$$
\begin{gathered}
V_{R}=R I_{0} e^{i \omega t} \\
V_{L}=L \frac{d I}{d t}=i L \omega I_{0} e^{i \omega t} \\
V_{C}=\frac{1}{C} \int I d t=\left(\frac{1}{i \omega C}\right) I_{0} e^{i \omega t}
\end{gathered}
$$

Chamando os coeficientes das equações (3) e (4) de $X_{L}$ e $X_{c}$, encontramos expressões análogas à lei de $\mathrm{Ohm}$ para esses dois elementos do circuito, onde $\mathrm{X}_{\mathrm{L}}$ e $\mathrm{X}_{\mathrm{c}}$ 
são dados em ohms e são chamados de reatância indutiva e capacitiva respectivamente. A tensão total nesses elementos em série será dada pela soma das tensões em cada um deles. Somando (2), (3) e (4) temos

$$
V^{*}=\left(R+i L \omega+\frac{1}{i \omega C}\right) I_{0} e^{i \omega t}
$$

Cuja parte real, pela relação de Euler para a exponencial complexa, nos dá

$$
\operatorname{Re}\left(V^{*}\right)=R I_{0} \cos \omega t+\left(\frac{1}{\omega C}-L \omega\right) I_{0} \operatorname{sen} \omega t
$$

Da equação (5), vemos que as reatâncias capacitiva e indutiva também podem ser representadas por grandezas complexas. A soma dessas reatâncias com a resistência (coeficiente entre parênteses na eq. 5), tem dimensão de resistência e define a impedância complexa.

$$
\begin{gathered}
Z^{*}=R+i L \omega+\frac{1}{i \omega C}=R+i\left(L \omega-\frac{1}{\omega C}\right) \\
Z^{*}=R+i\left(X_{L}-X_{C}\right)=Z e^{i \varphi}
\end{gathered}
$$

Conhecendo como se comportam a parte real e a parte imaginária da impedância de um circuito, é possível montar seu espectro de impedância plotando os valores da impedância real e complexa contra a frequência do sinal de entrada. Para este fím, podemos desprezar os termos associados ao indutor $\mathrm{L}$ dado que, na técnica da espectroscopia de impedância eletroquímica, o sistema estudado é aproximado para um sistema resistivo-capacitivo equivalente (CHINAGLIA, et al, 2008). Levando isso em conta, a equação (8) fica

$$
Z^{*}=R-i X_{C}
$$

Cujas partes real e imaginária são

$$
\begin{gathered}
\operatorname{Re}\left(Z^{*}\right)=R \\
\operatorname{Im}\left(Z^{*}\right)=-X_{C}=-\frac{1}{\omega C}
\end{gathered}
$$

Com isso, o espectro de impedância terá a seguinte forma

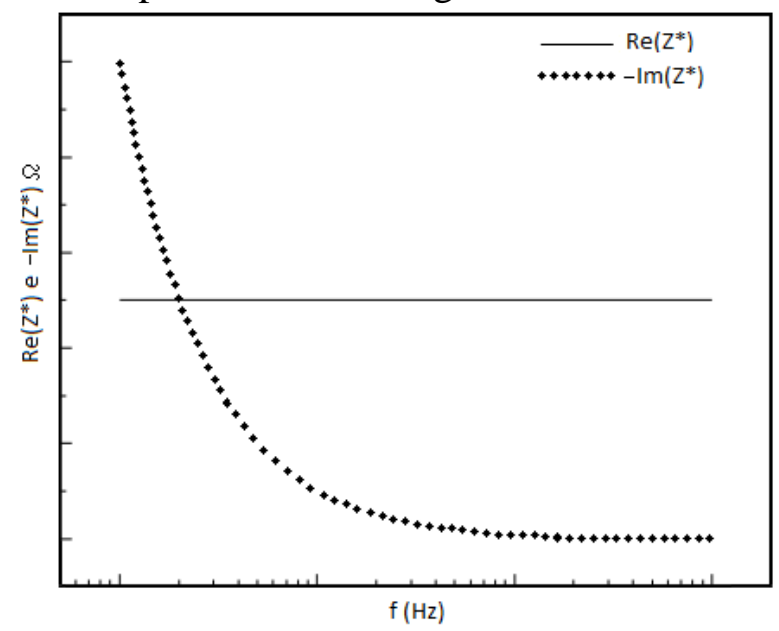

Figura 1: Ilustração do espectro de impedância para um circuito RC ideal em série.

Dada uma amostra como, por exemplo, uma célula eletroquímica, ao submete-la a um estímulo como uma corrente alternada igual à descrita acima, é possível levantar o espectro de impedância dessa amostra e ajustá-lo ao circuito resistivo-capacitivo equivalente. Dessa forma, podemos levantar os parâmetros da amostra e estudar como estes se comportam de modo a avaliar, por exemplo, como ela se degrada em diferentes 
condições ou caracterizar os materiais que a compõem (LOVEDAY, PETERSON e RODGERS, 2004).

\section{METODOLOGIA}

Utilizando o software Origin, foi possível implementar simulações do comportamento dos circuitos a serem estudados de modo a gerar dados que pudessem ser usados como base para comparação dos resultados a serem obtidos com a montagem experimental. $\mathrm{O}$ caso mais simples, um circuito puramente capacitivo que, no caso, consiste de um capacitor de $220 \mu \mathrm{F}$, foi simulado e seu espectro de impedância esperado é mostrado na figura 2 a seguir

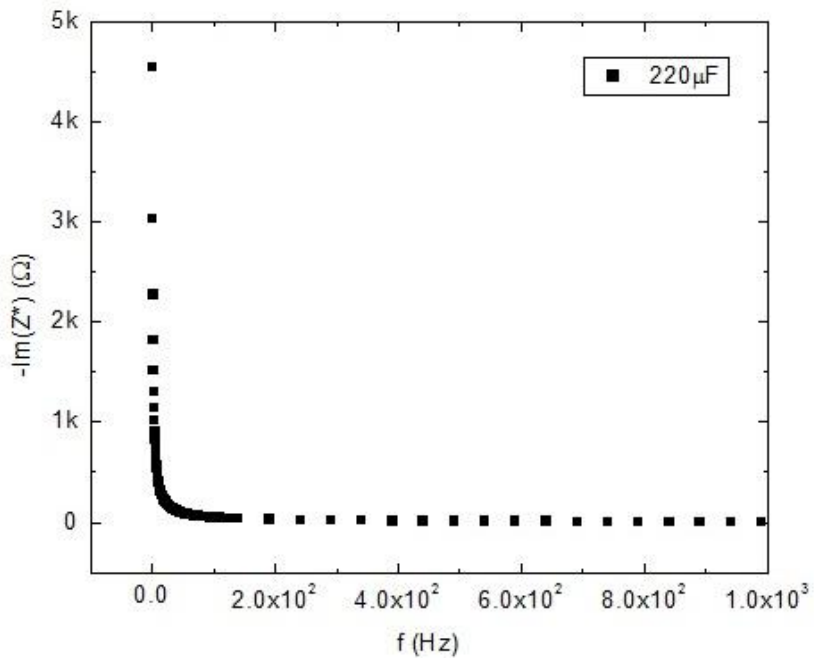

Figura 2: Simulação do espectro de impedância de um capacitor de $220 \mu \mathrm{F}$

O arranjo experimental consiste de um gerador de função para fornecer o potencial de excitação, um osciloscópio para leitura da mudança de fase entre o potencial de excitação e o sinal de saída e um aparato desenvolvido em uma caixa de montagem para manipulação dos circuitos utilizados. A figura 3 mostra um esquema da montagem.
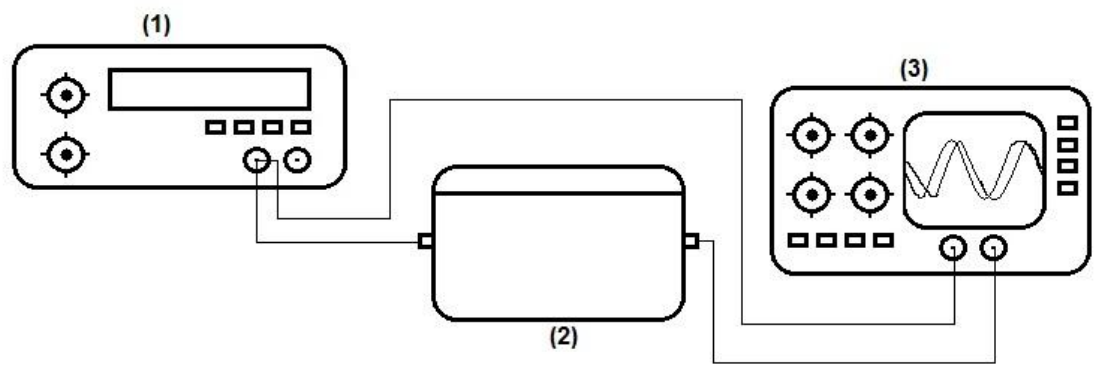

Figura 3: Esquema da montagem experimental. (1); Gerador de função, (2); caixa de montagem dos circuitos, (3); osciloscópio.

A caixa de montagem de circuitos (figura 4) consiste numa matriz de contatos ligada a conexões BNC para alimentação do sinal de entrada e extração do sinal de saída.
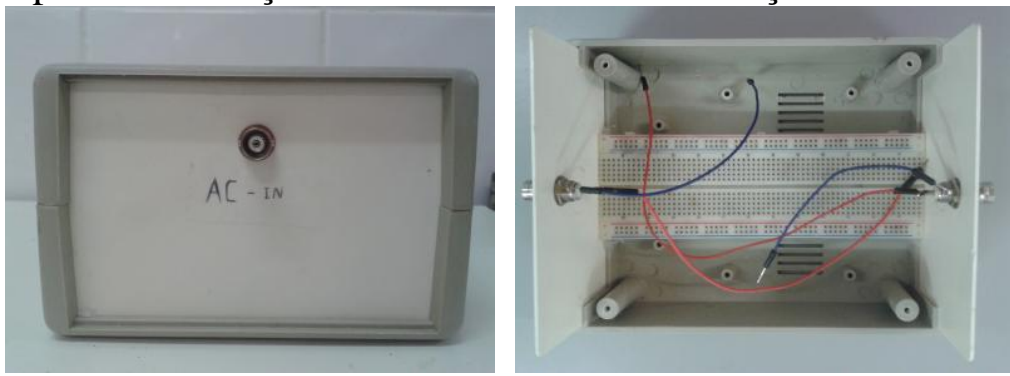

Figura 4: Aparato desenvolvido para montagem dos circuitos. 


\section{RESULTADOS E/OU DISCUSSÃO}

Construido o aparato e montado o arranjo experimental, foram realizados testes com circuitos resistivos e capacitivos a fim de registrar as alterações no potencial de excitação mediante análise do sinal de saída do circuito (figura 5).

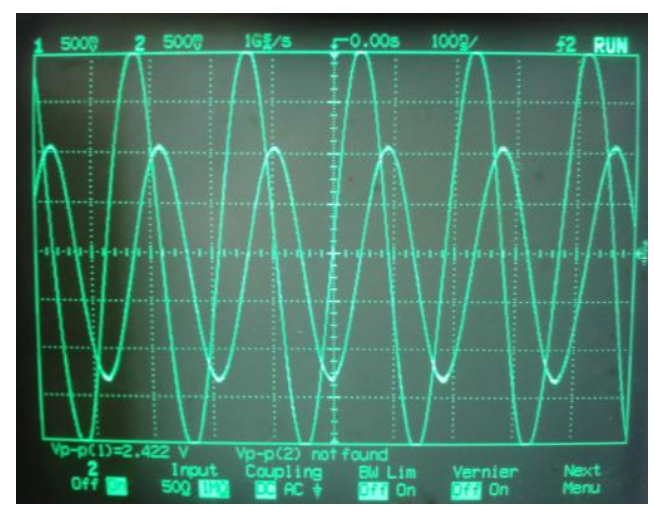

Figura 5: Alteração na fase do potencial de excitação para um capacitor de $220 \mu \mathrm{F}$.

O resultado acima é esperado de acordo com a literatura, pois um capacitor deve alterar a fase de um sinal AC que passa por ele. Isso sugere que o componente em questão deve obecer ao plot de Nyquist, no entanto, não foi possível registrar novas alterações na fase devido a limitações nos aparelhos utilizados.

\section{CONSIDERAÇÕES FINAIS}

Embora o aparato desenvolvido apresente os resultados esperados, que seria a leitura na mudança de fase do sinal de entrada, o sistema é limitado. $O$ resultado acima só pode ser observado a partir da faixa de $5 \mathrm{MHz}$, o que já é o limite do gerador de função disponível. Além disso, a resolução do osciloscópio pode não ser suficiente para registrar mudanças diminutas entre as fases dos dois canais. Realizando aprimoramentos nesses quesitos, o arranjo experimental desenvolvido poderá ser implementado em laboratórios didáticos para estudo do conceito de impedância e da técnica de espectroscopia de impedância eletroquímica.

\section{REFERÊNCIAS}

Impedance Spectroscopy; Theory, Experiment, and Applications, $2^{\text {nd }}$ ed. , E. Barsoukov, J.R. Macdonald, eds., Wiley Interscience Publications, 2005.

Electrochemical Methods; Fundamentals and Applications, A.J. Bard, L.R. Faulkner, Wiley Interscience Publications 2000.

CHINAGLIA, D. L. et al. Espectroscopia de impedância no laboratório de ensino. Revista Brasileira de Ensino de Física, p. 4504.1-4504.9, 2008.

LOVEDAY, David; PETERSON, Pete; RODGERS, Bob. Evaluation of organic coatings with electrochemical impedance spectroscopy. JCT coatings tech, v. 8, p. 4652, 2004. 